\title{
Sensing of Metal lons by Hybrid Systems of a Chiral Schiff Base Zn(II) Complex and Spiropyran
}

\author{
Masahiko Aonuma, Takashi Onodera, Satomi Morito, Asami Wada and Takashiro Akitsu* \\ Department of Chemistry, Faculty of Science, Tokyo University of Science, 1-3 Kagurazaka, Shinjuku-ku, \\ Tokyo 162-8601, Japan
}

\begin{abstract}
We have constructed three (hybrid) systems for quantitative fluorescence sensing of metal ions by using chiral Schiff base Zn(II) complexes. System 1 is a hybrid system composed of a trans-type chiral Schiff base Zn(II) complex and merocyanine $(\mathrm{Mc})$, which is open-form of spiropyran $(\mathrm{Sp})$ after photoisomerization. Depending on intermolecular interactions and quenching, increase $\left(\mathrm{Zn}^{2+}\right)$ or decrease $\left(\mathrm{Cu}^{2+}\right.$ and $\left.\mathrm{Gd}^{3+}\right)$ of fluorescence intensity of $\mathrm{Zn}$ (II) complex could be observed as functions of concentration of metal ions. System 2 is a sole component of a salen-type chiral Schiff base $\mathrm{Zn}$ (II) complex which can coordinate metal ions. After coordination of $\mathrm{Zn}^{2+}, \mathrm{Cu}^{2+}$, and $\mathrm{Gd}^{3+}$ ions, decreasing of fluorescence intensity could be found for all the cases for system 2 under the same condition to system 1 . System 3 is a hybrid system being consisted of a salen-type chiral Schiff base Zn(II) complex and Mc. Decrease or increase of fluorescence intensity is in agreement with intermolecular interactions, namely affinity for the $\mathrm{Zn}(\mathrm{II})$ complex is $\mathrm{Zn}^{2+}>$ $\mathrm{Cu}^{2+}>\mathrm{Gd}^{3+}$, whereas it is reverse order for Mc. The quantitative spectroscopic nature (detected as absorption, CD, and fluorescence) of these systems is predominantly attributed to both organic ligands and $\mathrm{Zn}$ (II) center in a probe complex.
\end{abstract}

Keywords: Ion sensor, Fluorescence spectra, Zn(II) complexes, Schiff base, Photochromism.

\section{INTRODUCTION}

We make use of finding and collection of metal ions in environment and human body, of which importance is increasing year by year [1-5]. For this reason specific detection of metal ions in complicate systems composed of many components is needed.

Moreover, a way for detection of specific metal ions controlled by external stimuli is also needed in order to avoid interference of other components. Among many metal ions as mentioned in the text of inorganic chemistry, $\mathrm{Zn}$ (II) ion is one of typical example of a trace essential element in human body [6], in particular important for metabolism [7] and parenteral nutrition [8]. Indeed, many fluorescent sensors for $\mathrm{Zn}$ (II) ion used in solutions have been reported so far [9-14], and one of typical recent examples exhibit a strong fluorescence response after coordination $\mathrm{Zn}$ (II) ion to non-fluorescent organic ligand [15]. This organic probe is a typical example of self-response fluorescent sensors to detect existence or concentration of $\mathrm{Zn}$ (II) ion in a pure system, which cannot control on purpose by external stimuli. Therefore, new ideas or ways for detection should be proposed to make use of external control [16-24]. In order to realize such requirement, we will examine multi-functional compounds or hybrid functional systems composed of both fluorescent part of $\mathrm{Zn}(\mathrm{II})$ ion and external controlling parts of several mechanisms.

*Address correspondence to this author at the Department of Chemistry, Faculty of Science, Tokyo University of Science,1-3 Kagurazaka, Shinjuku-ku, Tokyo 162-8601, Japan; Tel +81-3-5228-8271; Fax:+81-3-5261-4631;

E-mail: akitsu@rs.kagu.tus.ac.jp
In the course studies on organic/inorganic hybrid functional materials composed on photochromic organic compounds and chiral metal complexes [25], the present target is aiming at application for fluorescent probes for trace metal ions. According to this concept providing benefits to realize the requirement above, we have proposed and constructed three systems, System 1, System 2, and System 3 (Figures 1-3) working well as fluorescent sensors for specific metal ions after screening tests. Coordination of metal ions to be analyzed and emission of not only chiral Schiff base Zn(II) complexes [25, 26] but also photochromic spiropyran (Sp) or merocyanine (Mc) [2730] (quenching by energy transfer [31-33] between these components) as well as Schiff base [34] are a key principle of the present strategy of system design. Characteristic features and benefit if any of each system are summarized below:
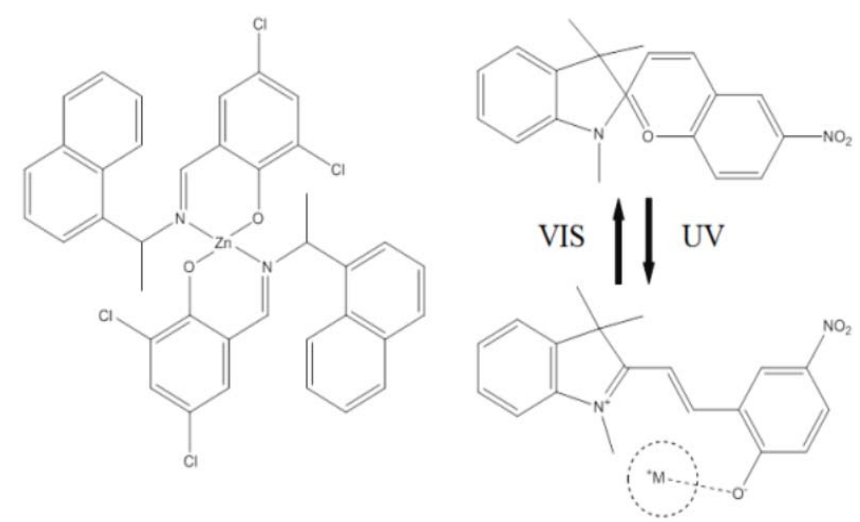

Figure 1: System 1: Trans-type chiral Schiff base $\mathrm{Zn}(\mathrm{II})$ complex (left) and Sp or Mc (right). 


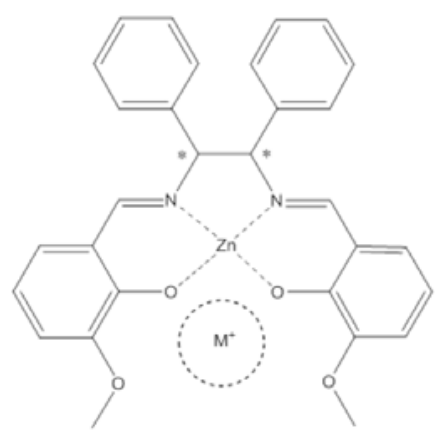

Figure 2: System 2: Salen-type chiral Schiff base Zn(II) complex.
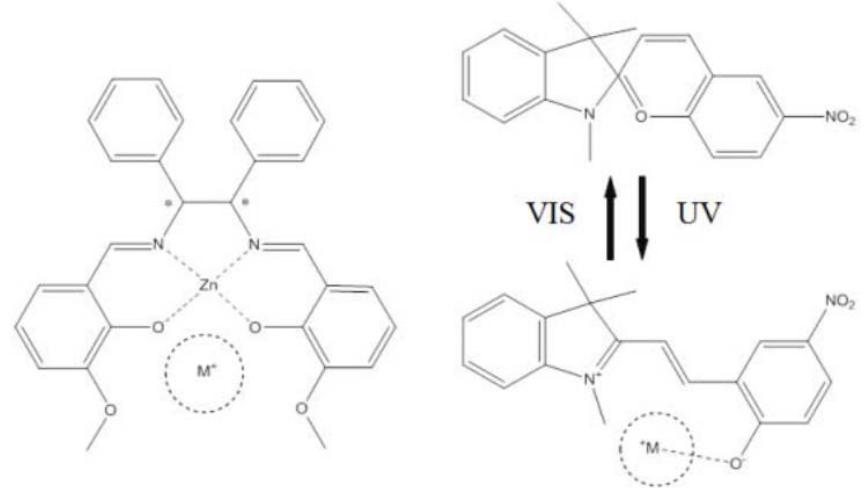

Figure 3: System 3: Salen-type chiral Schiff base $\mathrm{Zn}(\mathrm{II})$ complex (left) and $\mathrm{Sp}(\mathrm{Mc})$ (right).

As depicted in Figure 1, system 1 is composed of trans-type chiral Schiff base Zn(II) complexes [25], as a fluorescence probe with blue emission, and spiropyran (Sp) or merocyanine (Mc) [27-30]. It is well known that colorless closed-ring $\mathrm{Sp}$ occurs photoisomerization to purple open-ring $\mathrm{Mc}$ form, which is possible to coordinate metal ions, after UV irradiation. The reverse photoisomerization can occur after visible light irradiation. Among divalent ions of the first transition metals and trivalent ions of lanthanide metals, screening for coordination to $\mathrm{Mc}$ has also been investigated. Only $\mathrm{Zn}^{2+}, \mathrm{Cu}^{2+}$, and $\mathrm{Gd}^{3+}$ ions could indicate high quantitativities in methanol solutions. However, as increasing concentration of $\mathrm{Zn}^{2+}$ ions, fluorescence intensity of $\mathrm{Zn}$ (II) complexes is enhanced, while opposite tendency could be observed for $\mathrm{Cu}^{2+}$ and $\mathrm{Gd}^{3+}$ ions.

As depicted in Figure 2, system 2 is composed of salen-type chiral Schiff base Zn(II) complexes [26]. In order for comparison of qualitative coordination of $\mathrm{Zn}^{2+}$, $\mathrm{Cu}^{2+}$, and $\mathrm{Gd}^{3+}$ ions, salen-type chiral Schiff base $\mathrm{Zn}(\mathrm{II})$ complexes are employed for this system. The salentype ones can act as fluorescence probes as well as direct coordination sites for metal ions to be analyzed.
Not only $\mathrm{Zn}^{2+}, \mathrm{Cu}^{2+}$, and $\mathrm{Gd}^{3+}$ ions but also alkali and alkali earth ions were investigated for screening. Consequently, $\mathrm{Ba}^{2+}, \mathrm{Ca}^{2+}$, and $\mathrm{Sr}^{2+}$ ions could also exhibit fairly quantitative behavior and detection of $C D$ spectra as well as fluorescence spectra is proved to be useful for metal ion sensing.

As depicted in Figure 3, system 3 is hybrid systems composed of spiropyran (Sp) or merocyanine (Mc) and salen-type chiral Schiff base Zn(II) complexes [26]. It may be straightforwardly expected specific coordination of $\mathrm{Zn}^{2+}, \mathrm{Cu}^{2+}$, and $\mathrm{Gd}^{3+}$ ions, fluorescence quenching by $\mathrm{Mc}$ as well as $\mathrm{CD}$ detection of $\mathrm{Zn}$ (II) complexes, in addition, competition coordination of metal ions to be analyzed between two potential sites. However, the merit of this complicated system is elucidating mechanism of intermolecular interactions and spectroscopic features by means of metal coordination.

\section{METHODS}

\subsection{Materials}

Analytical pure Sp (Mc), 1', 3'-Dihydro-1', 3', 3'trimethyl-6-nitrospiro [2H-1-benzopyran- 2, 2'-(2H)indole], (Aldrich) and methanol (Kanto) were used as received without further purification. Trans-type [25] and salen-type [26] chiral Schiff base Zn(II) complexes were prepared according to the literature procedures.

\subsection{Experimental Conditions}

System 1: Screening of metal ions was carried out as follows: Hybrid system of $0.005 \mathrm{mM}\left(\mathrm{M}=\mathrm{mol} / \mathrm{dm}^{3}\right)$

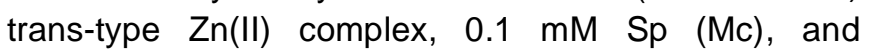
transition metal (II) ions of $\mathrm{Cu}^{2+}$ and $\mathrm{Zn}^{2+}$ or lanthanide (III) ions of $\mathrm{La}^{3+}, \mathrm{Ce}^{3+}, \mathrm{Nd}^{3+}, \mathrm{Sm}^{3+}, \mathrm{Eu}^{3+}, \mathrm{Gd}^{3+}, \mathrm{Tb}^{3+}$, $\mathrm{Er}^{3+}, \mathrm{Yb}^{3+}$, and $\mathrm{Lu}^{3+}(0.04,0.06$, and $0.08 \mathrm{mM})$ in a methanol solution. Then, we have measured fluorescence intensities of system 1 after UV irradiation $\left(\lambda_{\mathrm{ex}}=280 \mathrm{~nm}\right)$.

System 2: Screening of metal ions was carried out as follows: Hybrid system of $0.01 \mathrm{mM}$ salen-type $\mathrm{Zn}$ (II) complex and $\mathrm{Zn}^{2+}, \mathrm{Cu}^{2+}, \mathrm{Gd}^{3+}$ ions, all alkali and alkali earth metal ions $(0.0125,0.0500$, and $0.1000 \mathrm{mM})$ in a methanol solution for comparison with system 1 . Then, we have measured fluorescence intensities of system 2 $\left(\lambda_{\mathrm{ex}}=360 \mathrm{~nm}\right)$.

System 3: Testing $\mathrm{Zn}^{2+}, \mathrm{Cu}^{2+}$, and $\mathrm{Gd}^{3+}$ ions in a methanol solution under three conditions was carried out as follows: <1> Hybrid systems of $0.02 \mathrm{mM} \mathrm{Zn(II)}$ complex, $0.1 \mathrm{mM} \mathrm{Sp}(\mathrm{Mc})$, and $\mathrm{Gd}^{3+}$ ion $(0.0125$, 
$0.0250,0.0375,0.0500,0.0625,0.0750,0.0875$, and $0.1000 \mathrm{mM}$ ). <2> Hybrid systems of $0.02 \mathrm{mM} \mathrm{Zn(II)}$ complex, $0.05 \mathrm{mM} \mathrm{Sp}(\mathrm{Mc})$, and $\mathrm{Cu}^{2+}$ ion $(0.0025$, $0.0050,0.0075,0.0100,0.0125,0.0150,0.0175$, and $0.0200 \mathrm{mM}) .<3>$ Hybrid systems of $0.01 \mathrm{mM} \mathrm{Zn}(\mathrm{II})$ complex, $0.1 \mathrm{mM} \mathrm{Sp}(\mathrm{Mc})$, and $\mathrm{Zn}^{2+}$ ion $(0.0125$, $0.0250,0.0375,0.0500,0.0625,0.0750,0.0875$, and $0.1000 \mathrm{mM})$. Then, we have measured fluorescence intensities $\left(\lambda_{\mathrm{ex}}=360\right.$ and $\left.533 \mathrm{~nm}\right)$, and UV-vis and CD spectra for system 3 after UV irradiation for comparison with systems 1 and 2 .

\subsection{Physical Measurements}

Electronic spectra have been measured on a JASCO V-570 UV/VIS/NIR spectrophotometer in the range of $800-200 \mathrm{~nm}$ at $298 \mathrm{~K}$. Circular Dichroism (CD) spectra have been measured on a JASCO J-820 spectropolarimeter in the range of $800-200 \mathrm{~nm}$ at 298 $\mathrm{K}$. Fluorescence spectra have been recorded on a JASCO FP-6200 spectrophotometer at 298K. UV light irradiation (for opening $\mathrm{Sp}$ to form $\mathrm{Mc}$ ) has been carried out using a Hayashi UV lamp $\left(1.0 \mathrm{~mW} / \mathrm{cm}^{2}\right)$.

\section{RESULTS AND DISCUSSION}

\subsection{System 1}

As mentioned in METHODS, we have measured fluorescence intensity of system 1 with $\mathrm{Zn}^{2+}$ and $\mathrm{Gd}^{3+}$ ions after UV irradiation $\left(\lambda_{\mathrm{ex}}=280 \mathrm{~nm}\right)$. As shown in Figure 4, the fluorescence intensity $\left(\lambda_{\mathrm{em}}=460 \mathrm{~nm}\right)$ indicated linear correlation to the concentration of $\mathrm{Zn}^{2+}$ and $\mathrm{Gd}^{3+}$ ions.

As shown Figure 4, increasing of concentration of $\mathrm{Zn}^{2+}$ ion results in quantitatively increasing fluorescence intensity of a $\mathrm{Zn}$ (II) complex, while increasing of concentration of $\mathrm{Gd}^{3+}$ ion results in quantitatively decreasing fluorescence intensity of a $\mathrm{Zn}$ (II) complex. Partially unclear behavior of ions concentration dependence of intensity may be attributed to incomplete association of metal ions. Because slight deviation from perfectly linear correlation was observed (probably concerning coordination to $\mathrm{Mc}$ ) [27-30], data of $\mathrm{Cu}^{2+}$ was excluded from Figure 4. However, the tendency of $\mathrm{Cu}^{2+}$ ion is exactly similar to that of $\mathrm{Gd}^{3+}$ ion.

The reason of different tendency of $\mathrm{Zn}^{2+}$ ion and $\mathrm{Cu}^{2+}$ and $\mathrm{Gd}^{3+}$ ions may be elucidated by excitation energy of $\mathrm{Zn}(\mathrm{II})$ complex transfers to Mc-metal complex and intermolecular interaction between $\mathrm{Zn}$ (II) complex and Mc. $\mathrm{Zn}^{2+}$ ion coordinated to Mc also plays a similar
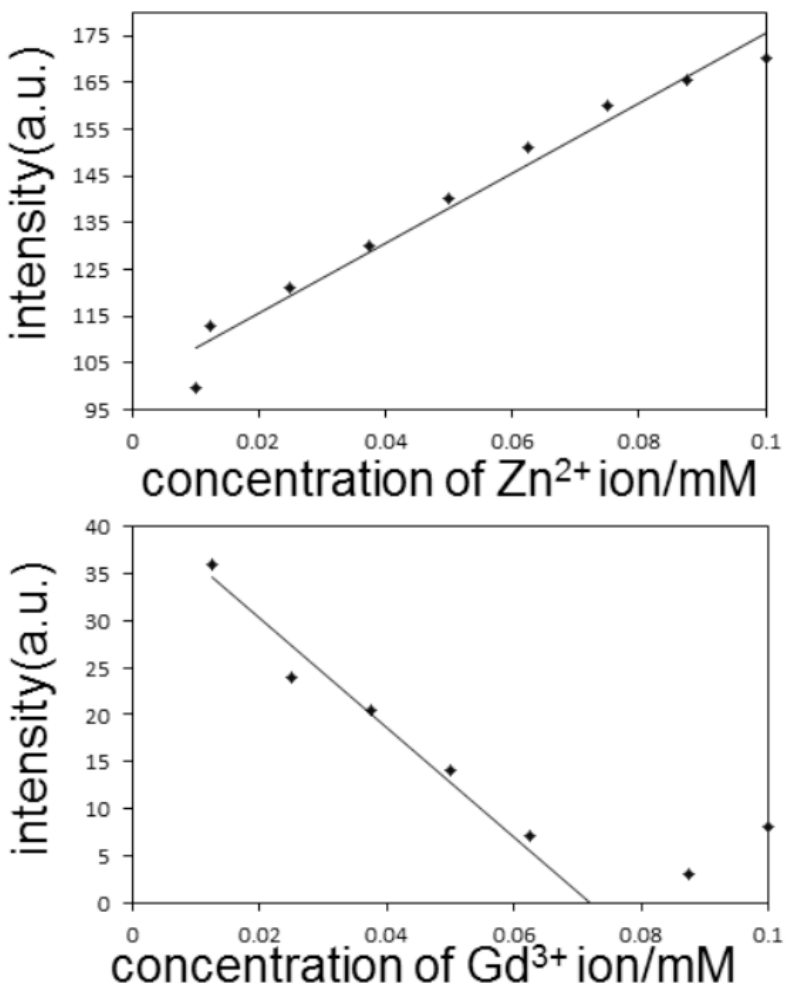

Figure 4: Calibration curves of fluorescence intensity $\left(\lambda_{\mathrm{ex}}=\right.$ $280 \mathrm{~nm}$ ) of a trans-type $\mathrm{Zn}(\mathrm{II})$ complex for system 1 as a function of concentration of analyzed $\mathrm{Zn}^{2+}$ (upper) and $\mathrm{Gd}^{3+}$ (lower) ions.

role as emissive complexes and it leads to enhance fluorescence intensity of a trans-type $\mathrm{Zn}$ (II) complex. On the other hand, paramagnetic $\mathrm{Cu}^{2+}$ and $\mathrm{Gd}^{3+}$ ions coordinated to Mc act as a good quencher which cause energy transfer enable to continue emission.

\subsection{System 2}

As for system 2, we have measured fluorescence intensity with $\mathrm{Cu}^{2+}, \mathrm{Zn}^{2+}$, and $\mathrm{Gd}^{3+}$ ions. As shown in Figure 5, the fluorescence intensity $\left(\lambda_{\mathrm{em}}=\right.$ c.a. $\left.480 \mathrm{~nm}\right)$ indicated similarly linear correlation to the concentration of $\mathrm{Zn}^{2+}, \mathrm{Cu}^{2+}, \mathrm{Gd}^{3+}$ ions, whose increasing/decreasing intensity as a function of ion concentration is different from system 1 . For comparison of system 1 , more well-coordinated but unreliable calibration curves for $\mathrm{Ba}^{2+}, \mathrm{Ca}^{2+}$, and $\mathrm{Sr}^{2+}$ ions are neglected (not shown).

Uniform decreasing of fluorescence intensity is explained that coordination of metal ions to be analyzed to the salen-type $\mathrm{Zn}$ (II) complex makes differences in electronic structures as binuclear metal complexes similarly, which do not indicate intense emission. Deviation from linearity for $\mathrm{Gd}^{3+}$ is ascribed to coordination. 

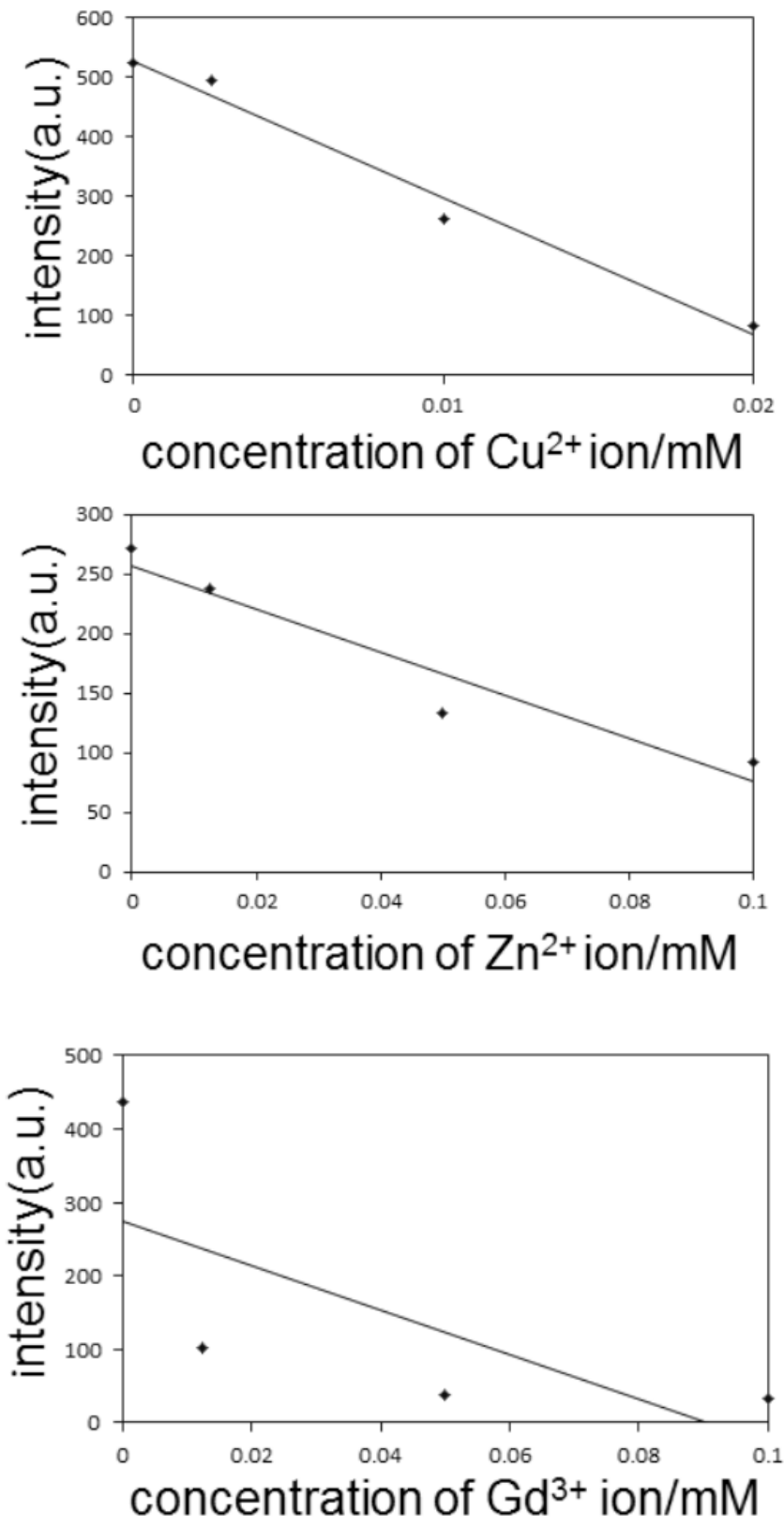

Figure 5: Calibration curves of fluorescence intensity $\left(\lambda_{\mathrm{ex}}=\right.$ $360 \mathrm{~nm}$ ) of a salen-type $\mathrm{Zn}$ (II) complex for system 2 as a function of with concentration of analyzed $\mathrm{Cu}^{2+}$ (upper), $\mathrm{Zn}^{2+}$ (middle), and $\mathrm{Gd}^{3+}$ (lower) ions.

\subsection{System 3}

As for system 3, we have measured UV-vis spectra with the corresponding $C D$ spectra (Figures 6, 8, 10) and fluorescence intensity (Figures $7,9,11$ ) with $\mathrm{Gd}^{3+}$ (Figures 6, 7), $\mathrm{Cu}^{2+}$ (Figures 8, 9), $\mathrm{Zn}^{2+}$ (Figures 10, 11) ions before and after UV irradiation. Although these are hybrid systems, the CD spectra provide selective information of chiral species (chiral salen-type Zn(II) complexes). Because only system 3 indicated clear spectral changes detectable with $C D$ spectra. Additionally, selective information based on
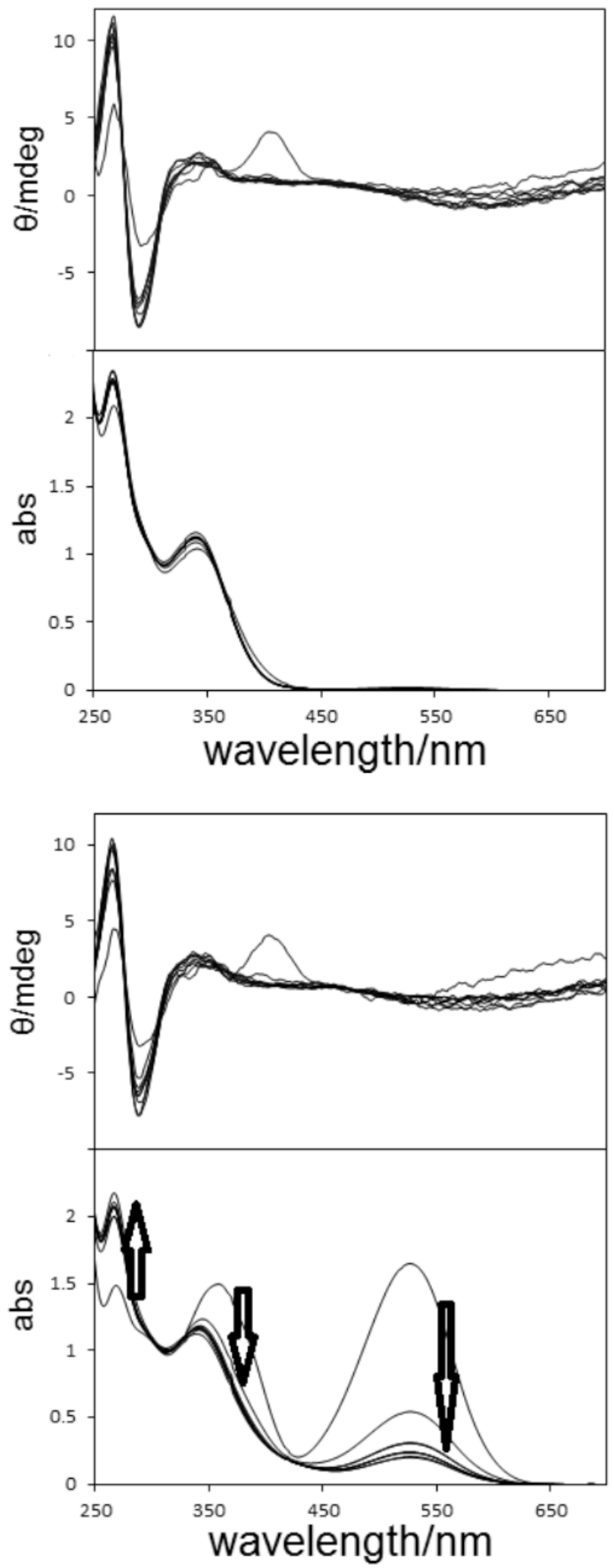

Figure 6: Comparison of CD and UV-vis spectra of system 3 with $\mathrm{Gd}^{3+}$ ion before (upper) and after (lower) irradiation of UV light. Arrows emphasize spectral changes due to formation of Mc after UV light irradiation.

fluorescence spectra of a salen-type $\mathrm{Zn}$ (II) complex $\left(\lambda_{\mathrm{em}}=\right.$ c.a. $\left.480 \mathrm{~nm}\right)$ and $\mathrm{Mc}\left(\lambda_{\mathrm{em}}=620 \mathrm{~nm}\right)$ can be 
obtained by changing excitation wavelengths. Moreover, these spectral changes before and after irradiation of UV light are in agreement with $\mathrm{Sp}$ (only sites of a salen-type $\mathrm{Zn}$ (II) complex can coordinate metal ions to be analyzed) and Mc (both sites of $\mathrm{Mc}$ and a salen-type $\mathrm{Zn}(\mathrm{II})$ complex can coordinate metal ions to be analyzed) to investigate competition coordination.

In Figures 7, 9, 11, obviously common CD peaks for system 3 at 260 and $280 \mathrm{~nm}$ or $410 \mathrm{~nm}$ are assigned to $\pi-\pi^{*}$ band of phenyl groups or salicylaldehyde moiety, respectively. Obviously common absorption peaks for system 3 at $260 \mathrm{~nm}, 340 \mathrm{~nm}$, and $530 \mathrm{~nm}$ are assigned to $\pi-\pi^{*}$ band of phenyl groups or salicylaldehyde moiety, and Mc, respectively.
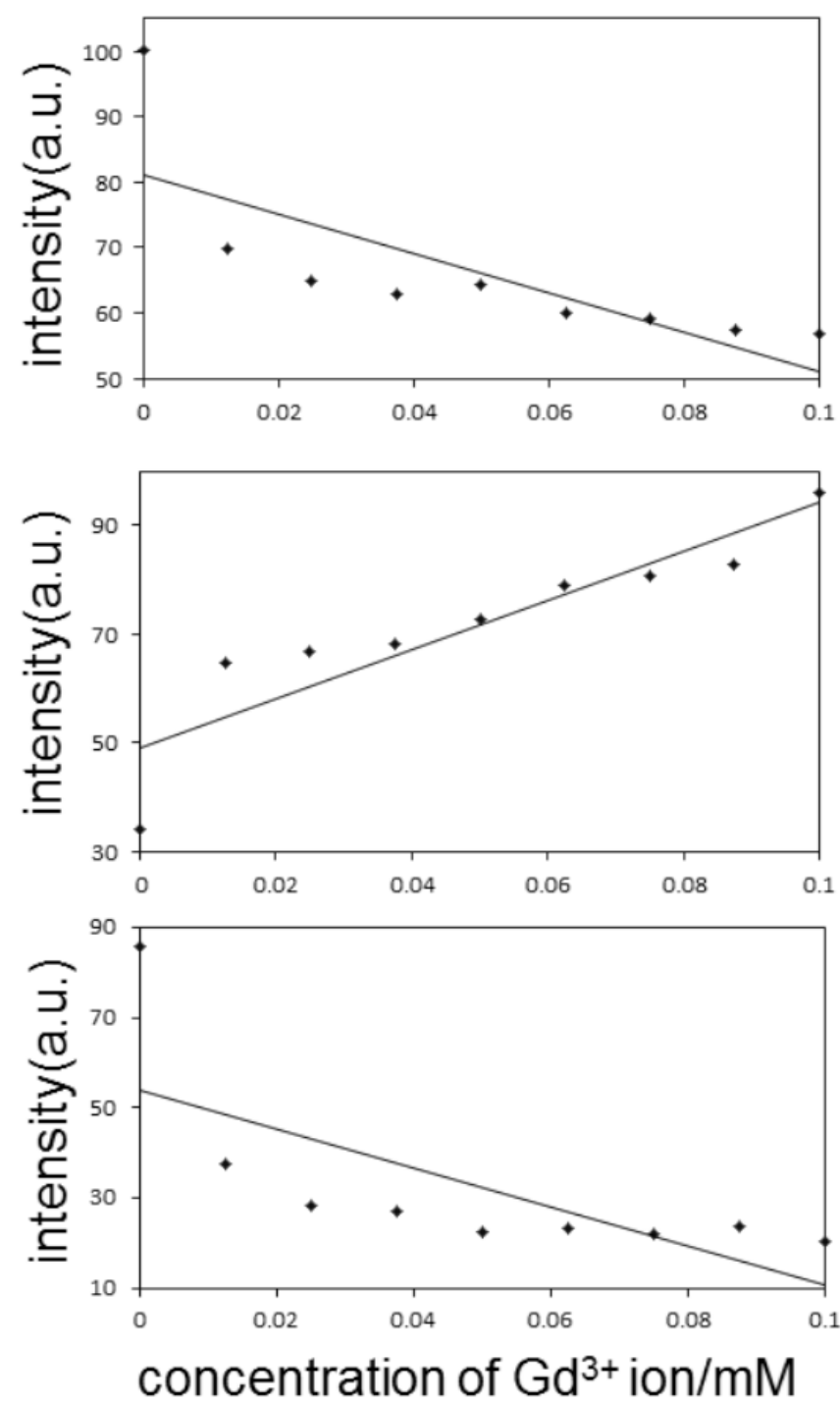

Figure 7: comparison of calibration curves of fluorescence intensity spectra of system 3 with $\mathrm{Gd}^{3+}$ ion $\left(\lambda_{\mathrm{ex}}=360 \mathrm{~nm}\right.$ : before UV irradiation (upper) and after UV irradiation (middle) and $\lambda_{\mathrm{ex}}=533 \mathrm{~nm}$ (lower)).
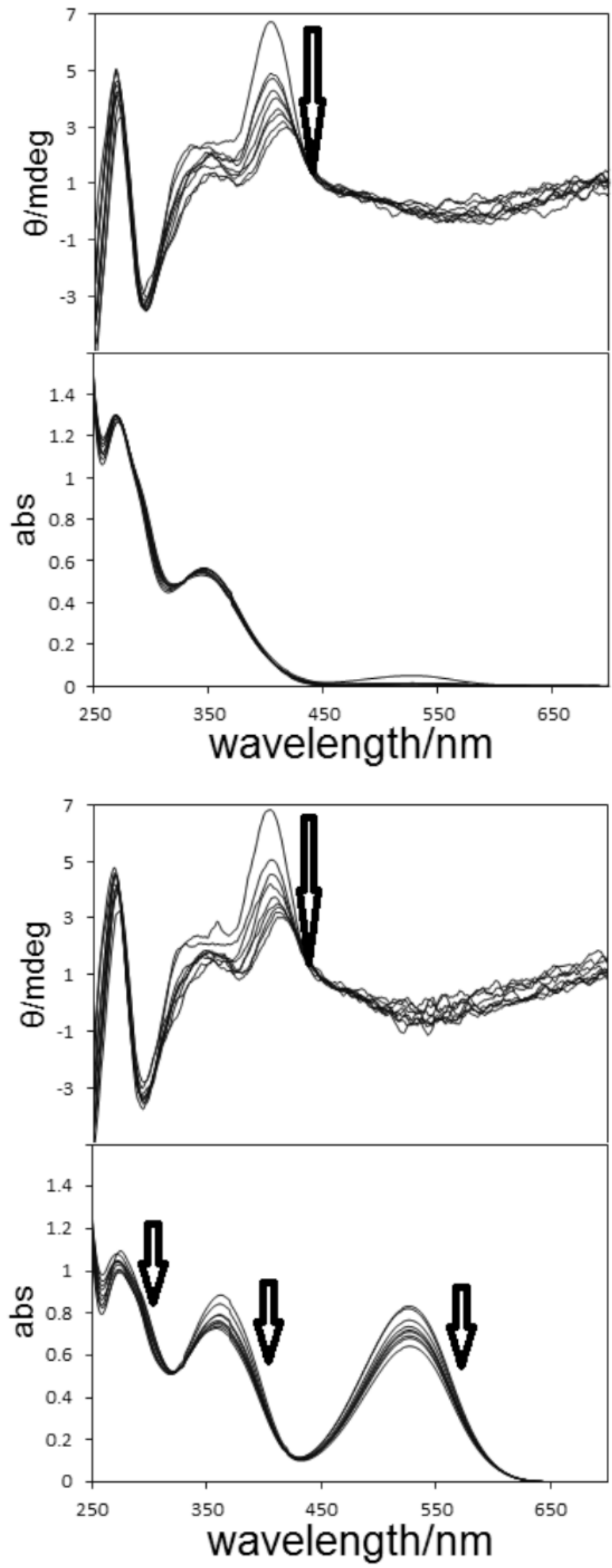

Figure 8: Comparison of CD and UV-vis spectra of system 3 with $\mathrm{Cu}^{2+}$ ion before (upper) and after (lower) irradiation of UV light. Arrows emphasize spectral changes due to formation of Mc after UV light irradiation. 

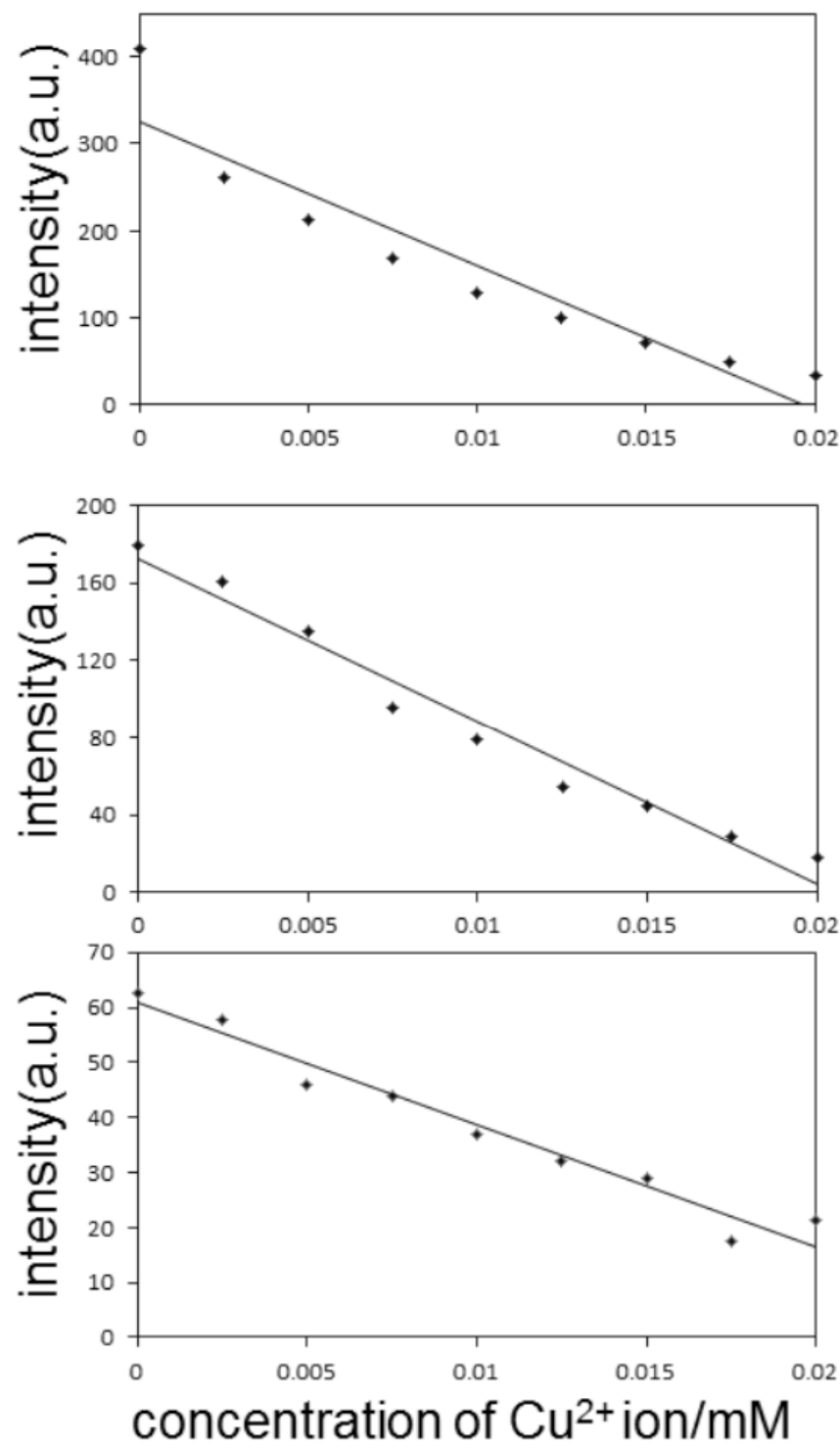

Figure 9: comparison of calibration curves of fluorescence intensity spectra of system 3 with $\mathrm{Cu}^{2+}$ ion $\left(\lambda_{\mathrm{ex}}=360 \mathrm{~nm}\right.$ : before UV irradiation (upper) and after UV irradiation (middle) and $\lambda_{\mathrm{ex}}=533 \mathrm{~nm}$ (lower)).

In the case of $\mathrm{Gd}^{3+}$ ion, after irradiation of UV light, CD peaks at $280 \mathrm{~nm}$ indicated definite changes, while those at $410 \mathrm{~nm}$ indicated little changes. Absorption peaks at $260 \mathrm{~nm}$ increased, while the peaks at 360 and $530 \mathrm{~nm}$ decreased. Fluorescence intensity increased for $\mathrm{Zn}(\mathrm{II})$ complex $\left(\lambda_{\mathrm{ex}}=360 \mathrm{~nm}\right)$ and decrease for Mc $\left(\lambda_{\mathrm{ex}}=533 \mathrm{~nm}\right)$ after UV irradiation.

In the case of $\mathrm{Cu}^{2+}$ ion, after irradiation of UV light, $C D$ peaks at 260, 280, and $410 \mathrm{~nm}$ decreased quantitatively. UV-vis peaks at $260 \mathrm{~nm}$ increased, while the peaks at 360 and $530 \mathrm{~nm}$ decreased. The magnitude of decrease of the peak at $530 \mathrm{~nm}$ of $\mathrm{Cu}^{2+}$ ion is much smaller than that of $\mathrm{Gd}^{3+}$ ion. Fluorescence intensity decreased for $\mathrm{Zn}(\mathrm{II})$ complex $\left(\lambda_{\mathrm{ex}}=360 \mathrm{~nm}\right)$
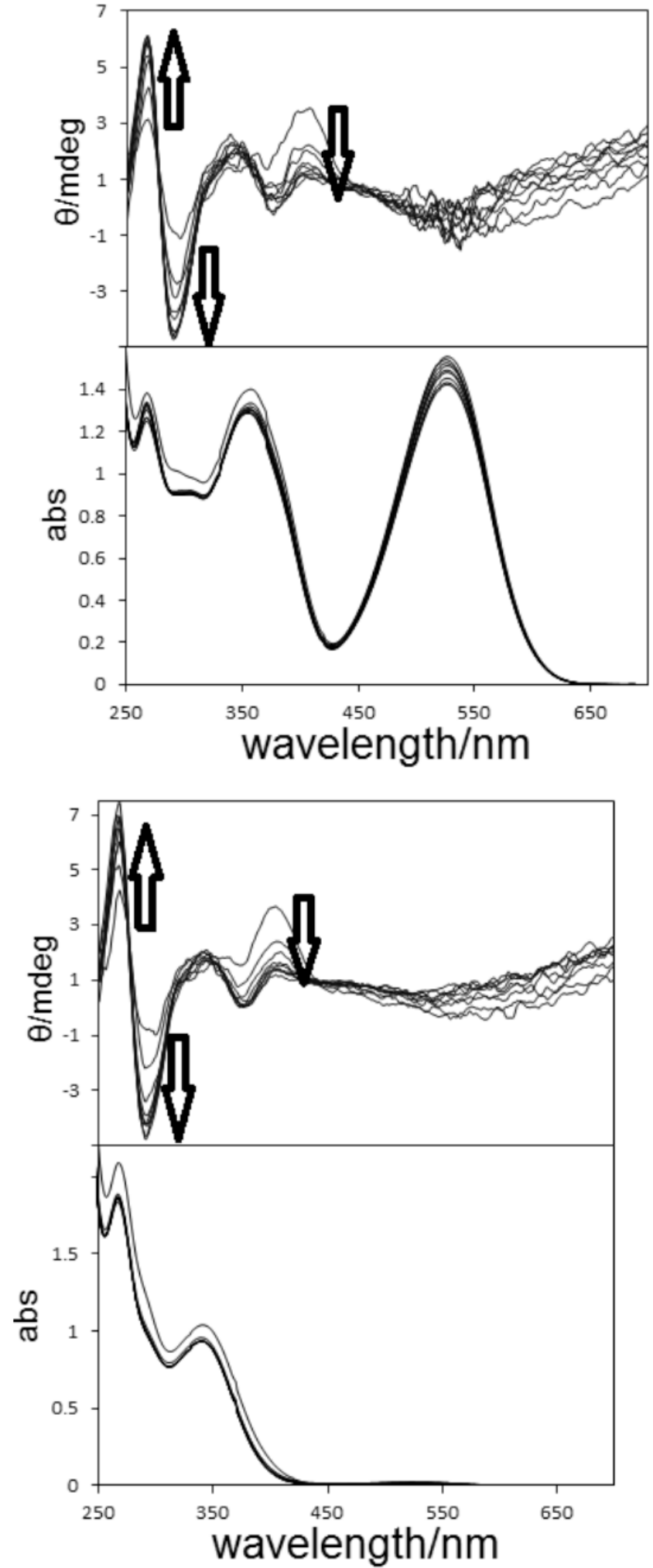

Figure 10: Comparison of $C D$ and UV-vis spectra of system 3 with $\mathrm{Zn}^{2+}$ ion before (upper) and after (lower) irradiation of UV light. Arrows emphasize spectral changes due to formation of Mc after UV light irradiation

after UV irradiation. However, the peaks of Mc $\left(\lambda_{\mathrm{ex}}=\right.$ $533 \mathrm{~nm}$ ) is not reproducible. 

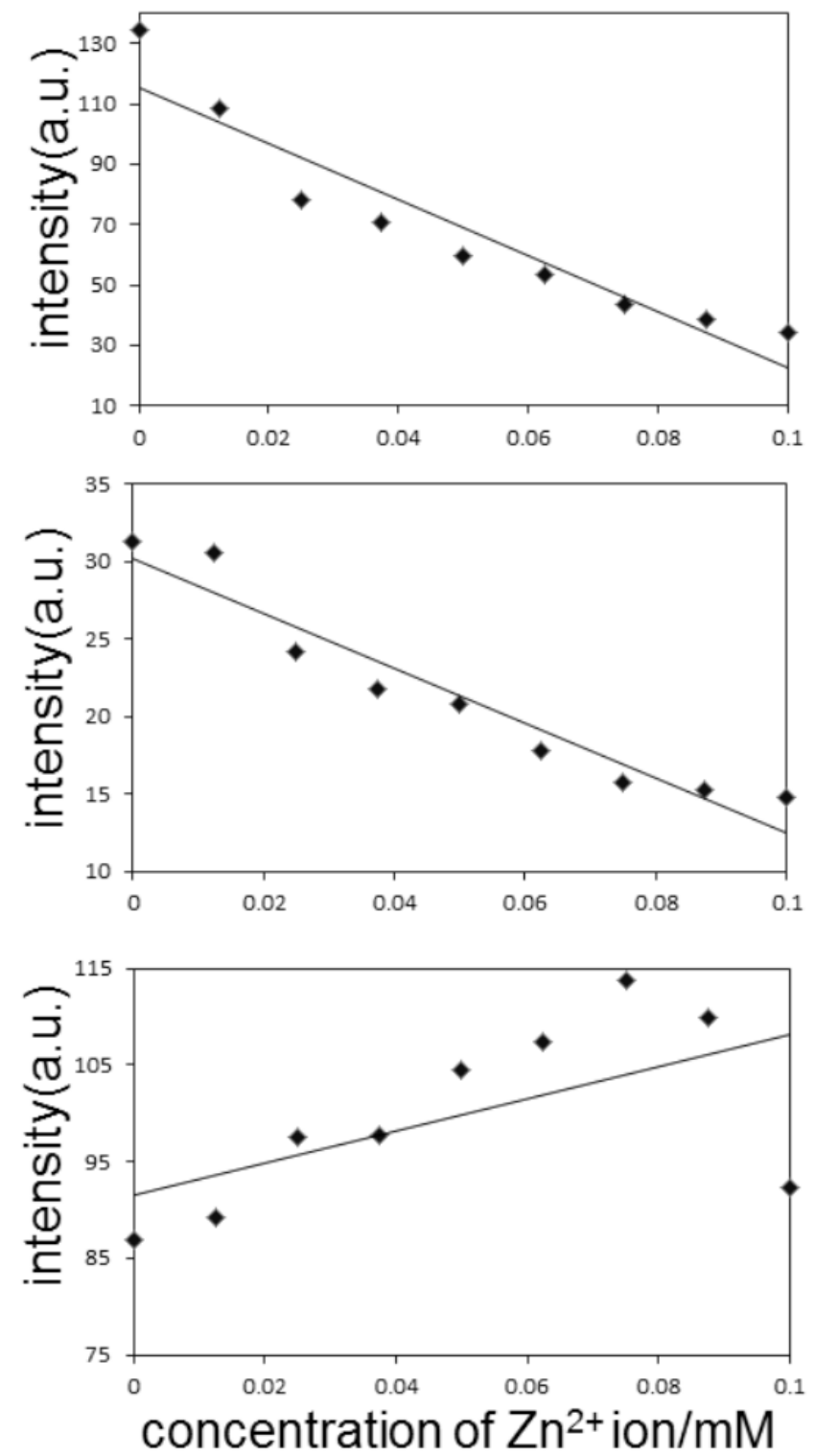

Figure 11: comparison of calibration curves of fluorescence intensity spectra of system 3 with $\mathrm{Zn}^{+}$ion $\left(\lambda_{\mathrm{ex}}=360 \mathrm{~nm}\right.$ : before UV irradiation (upper) and after UV irradiation (middle) and $\lambda_{\mathrm{ex}}=533 \mathrm{~nm}$ (lower)).

In the case of $\mathrm{Zn}^{2+}$ ion, quantitative spectral changes could be observed for CD bands at 260, 280, and $410 \mathrm{~nm}$ and little spectral changes also could be observed for UV-vis bands at $530 \mathrm{~nm}$ in contrast to $\mathrm{Cu}^{2+}$ or $\mathrm{Gd}^{3+}$ ion. However, fluorescence intensity linearly decreased for $\mathrm{Zn}(\mathrm{II})$ complex $\left(\lambda_{\mathrm{ex}}=360 \mathrm{~nm}\right)$ and almost linearly increased for Mc $\left(\lambda_{\mathrm{ex}}=533 \mathrm{~nm}\right)$ as a function of concentration of doped $\mathrm{Zn}^{2+}$ ion. Partially unclear behavior of ions concentration dependence of intensity may be attributed to incomplete association of metal ions.

Accordingly, competitive coordination and changes after UV irradiation for system 3 may be summarized as follows: It seems that $\mathrm{Gd}^{3+}$ ion transferred to from $\mathrm{Zn}$ (II) complex to Mc. Competitive coordination of $\mathrm{Cu}^{2+}$ ion to $\mathrm{Zn}$ (II) complex (major) and Mc (minor) seem to occur. It appears $\mathrm{Zn}^{2+}$ ion coordinates to $\mathrm{Zn}$ (II) complex consistently.

Furthermore, according to UV-vis, CD and fluorescence spectra, coordination affinity to salen chiral $\mathrm{Zn}(\mathrm{II})$ complex in system 3 are found to be $\mathrm{Zn}^{2+}>$ $\mathrm{Cu}^{2+}>\mathrm{Gd}^{3+}$ and that to $\mathrm{Mc}$ is in reverse order. This result doesn't contradict that in system 1. Making use of these properties, we can remove these metals selectively in soil and water, including heavy metals and also apply those to a chromatography, an ion exchange resin and detoxification effects.

\section{CONCLUSION}

In summary, it should be noted that excitation and fluorescence wavelengths are $\lambda_{\mathrm{ex}}=260 \mathrm{~nm}$ and $\lambda_{\mathrm{em}}=$ $460 \mathrm{~nm}$ for a trans-type $\mathrm{Zn}$ (II) complex, $\lambda_{\mathrm{ex}}=360 \mathrm{~nm}$ and $\lambda_{\mathrm{em}}=480 \mathrm{~nm}$ for a salen-type $\mathrm{Zn}$ (II) complex, and $\lambda_{\mathrm{ex}}=533 \mathrm{~nm}$ and $\lambda_{\mathrm{em}}=620 \mathrm{~nm}$ for Mc. By using the results, we have constructed and tested three (hybrid) systems for metal ion sensing for the first time. System 1 elucidates that only $\mathrm{Zn}^{2+}, \mathrm{Cu}^{2+}$, and $\mathrm{Gd}^{3+}$ ions exhibit quantitativities of fluorescence intensities of (not directly coordinating $\mathrm{Mc}$ but) trans-type $\mathrm{Zn}(\mathrm{II})$ complexes as functions of concentration of ions to be analyzed. System 2 elucidates that $\mathrm{Zn}^{2+}, \mathrm{Cu}^{2+}$, and $\mathrm{Gd}^{3+}$ ions (as well as $\mathrm{Ba}^{2+}, \mathrm{Ca}^{2+}$, and $\mathrm{Sr}^{2+}$ ions more fairly) exhibit quantitative decrease of fluorescence intensities of salen-type $\mathrm{Zn}$ (II) complexes as a function of directly coordinated metal ions. System 3 elucidates not only experimentally confirming facts of the quantitative changes of fluorescence intensities but also competitive coordination mechanism between salen-type $\mathrm{Zn}$ (II) complexes and $\mathrm{Mc}$ of $\mathrm{Zn}^{2+}, \mathrm{Cu}^{2+}$, and $\mathrm{Gd}^{3+}$ ions in methanol solutions. Development of application to ion sensing with supramolecular systems can be also expected.

\section{REFERENCES}

[1] Shi S, Zhang Y, Chen X, Peng M. Investigation of Flavonoids Bearing Different Substituents on Ring $\mathrm{C}$ and Their $\mathrm{Cu}^{2+}$ Complex Binding with Bovine Serum Albumin: Structure Affinity Relationship Aspects. J Agric Food Chem 2011; 59: 10761-69.

http://dx.doi.org/10.1021/jf2027523

[2] Chiu Y-C, Okajima T, Murakawa T, Uchida M, Taki M, Hirota $\mathrm{S}$, et al. Kinetic and Structural Studies on the Catalytic Role of the Aspartic Acid Residue Conserved in Copper Amine Oxidase. Biochemistry 2006; 45: 4105-120.

http://dx.doi.org/10.1021/bi052464l 
[3] Coughtrey PJ, Martin MH. The uptake of lead, zinc, cadmium, and copper by the pulmonate mollusc, Helix aspersa muller, and its relevance to the monitoring of heavy metal contamination of the environment. Oecologia 1977; 27 : 65-74.

http://dx.doi.org/10.1007/BF00345685

[4] VanZile ML, Cosper NJ, Scott RA, Giedroc DP. The Zinc Metalloregulatory Protein Synechococcus PCC7942 SmtB Binds a Single Zinc lon per Monomer with High Affinity in a Tetrahedral Coordination Geometry. Biochemistry 2000; 39: 11818-29.

http://dx.doi.org/10.1021/bi001140o

[5] Major DT, Gao J. A Combined Quantum Mechanical and Molecular Mechanical Study of the Reaction Mechanism and a-Amino Acidity in Alanine Racemase. J Am Chem Soc 2006; 128: 16345-57. http://dx.doi.org/10.1021/ja066334r

[6] McClung JP, Scrimgeour AG. Zinc: an essential trace element with potential benefits to soldiers. Mil Med 2005: $170 ; 1048-52$.

[7] Smith Jr. JC, McDaniel EG, Fan FF, Halsted JA. Zinc: A Trace Element Essential in Vitamin A Metabolism. Science 1973; 181: 954-55.

http://dx.doi.org/10.1126/science.181.4103.954

[8] Jeejeebhoy K. Zinc: an essential trace element for parenteral nutrition. Gastroenterology 2009; 137: S7-12. http://dx.doi.org/10.1053/j.gastro.2009.08.014

[9] Ojida A, Takashima I, Kohira T, Nonaka H, Hamachi I. TurnOn Fluorescence Sensing of Nucleoside Polyphosphates Using a Xanthene-Based Zn(II) Complex Chemosensor. J Am Chem Soc 2008; 130: 12095-101 http://dx.doi.org/10.1021/ja803262w

[10] Hou J, Song F, Wang L, Wei G, Cheng Y, Zhu C. In Situ Generated 1:1 Zn(II)-Containing Polymer Complex Sensor for Highly Enantioselective Recognition of N-Boc-Protected Alanine. Macromolecules 2012; 45: 7835-42. http://dx.doi.org/10.1021/ma301553y

[11] Pandey R, Kumar P, Singh AK, Shahid M, Li P-Z, Singh SK, et al. Fluorescent Zinc(II) Complex Exhibiting "On-Off-On" Switching Toward $\mathrm{Cu}^{2+}$ and $\mathrm{Ag}^{+}$lons. Inorg Chem 2011; 50: 3089-97.

http://dx.doi.org/10.1021/ic1018086

[12] Germain ME, Vargo TR, McClure BA, Rack JJ, van Patten PG, Odoi $M$, et al. Quenching Mechanism of Zn(Salicylaldimine) by Nitroaromatics. Inorg Chem 2008; 47: 6203-11.

http://dx.doi.org/10.1021/ic702469q

[13] Crivat G, Kikuchi K, Nagano T, Priel T, Hershfinkel M, Sekler I, et al. Fluorescence-Based Zinc Ion Sensor for Zinc Ion Release from Pancreatic Cells. Anal Chem 2006; 78: 5799804.

http://dx.doi.org/10.1021/ac060764i

[14] Khatua S, Choi SH, Lee J, Kim K, Do Y, Churchill DG. Aqueous Fluorometric and Colorimetric Sensing of Phosphate lons by a Fluorescent Dinuclear Zinc Complex. Inorg Chem 2009; 48: 2993-99.

http://dx.doi.org/10.1021/ic8022387

[15] Lin H-Y, Cheng P-Y, Wan C-F, Wu A-T. A turn-on and reversible fluorescence sensor for zinc ion. Analyst 2012: $137 ; 4415-17$.

http://dx.doi.org/10.1039/c2an35752f

[16] Byrne RJ, Stitzel SE, Diamond D. Photo-regenerable surface with potential for optical sensing. J Mater Chem 2006: 16; 1332-37. http://dx.doi.org/10.1039/b516400a

[17] Sumalekshmy S, Fahrni CJ. Metal-lon-Responsive Fluorescent Probes for Two-Photon Excitation Microscopy. Chem Mater 2011; 23: 483-500.

http://dx.doi.org/10.1021/cm1021905
[18] Yuasa J, Fukuzumi S. OFF-OFF-ON Switching of Fluorescence and Electron Transfer Depending on Stepwise Complex Formation of a Host Ligand with Guest Metal lons. J Am Chem Soc 2008; 130: 566-75.

http://dx.doi.org/10.1021/ja0748480

[19] Germain ME, Knapp MJ. Turn-on Fluorescence Detection of $\mathrm{H}_{2} \mathrm{O}_{2}$ and TATP. Inorg Chem 2008; 47: 9748-50. http://dx.doi.org/10.1021/ic801317x

[20] Rosell FI, Mauk MR, Mauk AG. pH- and Metal lon-Linked Stability of the Hemopexin-Heme Complex. Biochemistry 2005; 44: 1872-79. http://www.ncbi.nlm.nih.gov/pubmed/ 15697213 http://dx.doi.org/10.1021/bi0480077

[21] Dean NE, Hancock RD, Cahill CL, Frisch M. Affinity of the Highly Preorganized Ligand PDA (1,10-Phenanthroline-2,9dicarboxylic acid) for Large Metal lons of Higher Charge. A Crystallographic and Thermodynamic Study of PDA Complexes of Thorium(IV) and the Uranyl(VI) ion. Inorg Chem 2008; 47: 2000-10. http://dx.doi.org/10.1021/ic701574

[22] Lo H-S, Yip S-K, Wong KM-C, Zhu N, Yam VW-W. Selective Luminescence Chemosensing of Potassium lons Based on a Novel Platinum(II) Alkynylcalix[4]crown-5 Complex. Organometallics 2006; 25: 3537-40. http://dx.doi.org/10.1021/om060218f

[23] Zhao Q, Li F, Liu S, Yu M, Liu Z, Yi T, Huang C. Highly Selective Phosphorescent Chemosensor for Fluoride Based on an Iridium(III) Complex Containing Arylborane Units. Inorg Chem 2008; 47: 9256-64. http://dx.doi.org/10.1021/ic800500c

[24] Männel-Croisé C, Zelder F. Complex Samples Cyanide Detection with Immobilized Corrinoids. Appl Mater Interfaces 2012; 4: 725-29. http://dx.doi.org/10.1021/am201357u

[25] Akitsu T. Photofunctional supramolecular solution systems of Chiral Schiff Base Nickel(II), Copper(II), and Zinc(II) complexes and photochromic azobenzenes. Polyhedron 2007; 26: 2527-35 http://dx.doi.org/10.1016/j.poly.2006.12.031

[26] Hiratsuka T, Shibata H, Akitsu T. Structures and Properties of $3 d-4 f$ and $3 d$ Chiral Schiff base Complexes. Crystallography 2010; 3: 45-64. https://www.novapublishers. com/catalog/product info.php?products_id=36359\&osCsid=1 68c08748e890891d8335a0f23b338ea

[27] Arai K, Shitara Y, Ohyama T. Preparation of photochromic spiropyrans linked to methyl cellulose and photoregulation of their properties. J Mater Chem 1996; 6: 11-14. http://dx.doi.org/10.1039/jm9960600011

[28] Wojtyk JTC, Kazmaier PM, Buncel E. Effects of metal ion complexation on the spiropyran-merocyanine interconversion: development of a thermally stable photoswitch. Chem Commun 1998; 16: 1703-704. http://dx.doi.org/10.1039/a804908d

[29] Shao N, Wang H, Gao X-D, Yang R-H, Chan W-H Spiropyran-Based Fluorescent Anion Probe and its Application for Urinary Pyrophosphate Detection. Anal Chem 2010; 82: 4628-36. http://dx.doi.org/10.1021/ac1008089

[30] Xie X, Mistlberger G, Bakker E. Reversible Photodynamic Chloride-Selective Sensor Based on Photochromic Spiropyran. J Am Chem Soc 2012; 134: 16929-32. http://dx.doi.org/10.1021/ja307037z

[31] Shepherd GB, Papadakis N, Hammes GG. Fluorescence Energy-Transfer Measurements between Coenzyme $A$ and Flavin Adenine Dinucleotide Binding Sites of the Escherichia coli Pyruvate Dehydrogenase Multienzyme Complex. Biochemistry 1976; 15: 2888-93.

http://dx.doi.org/10.1021/bi00658a029 
[32] Takashi R. Fluorescence Energy Transfer between Subfragment- 1 and Actin Points in the Rigor Complex of Actosubfragment- I. Biochemistry 1979; 18: 5164-69. http://dx.doi.org/10.1021/bi00590a021

[33] Shepherd GB, Hammes GG. Fluorescence Energy Transfer Measurements in the Pyruvate Dehydrogenase Multienzyme Complex from Escherichia coli with Chemically Modified Lipoic Acid. Biochemistry 1977; 16: 5234-41. http://dx.doi.org/10.1021/bi00643a012
[34]

Liu H, Fu Z, Xu K, Cai H, Liu X, Chen M. Structure-Property Relationship of Highly $\pi$-Conjugated Schiff-Base Moiety in Liquid Crystal Diepoxide Polymerization and Mesophases Stabilization. J Phys Chem B 2011; 115: 7568-77. http://dx.doi.org/10.1021/jp202998x

Received on 04-03-2013

Accepted on 05-05-2013

Published on 27-05-2013

DOI: http://dx.doi.org/10.6000/1929-5030.2013.02.02.3

(C) 2013 Aonuma et al.; Licensee Lifescience Global.

This is an open access article licensed under the terms of the Creative Commons Attribution Non-Commercial License (http://creativecommons.org/licenses/by-nc/3.0/) which permits unrestricted, non-commercial use, distribution and reproduction in any medium, provided the work is properly cited. 